\title{
Survival Model of Drivers' Speed Reduction Time at Bicycle Crossroads: A Driving Simulator Study
}

\author{
Francesco Bella $\mathbb{D}$ and Manuel Silvestri \\ Roma TRE University, Department of Engineering, Via Vito Volterra n. 62, 00146 Rome, Italy \\ Correspondence should be addressed to Francesco Bella; francesco.bella@uniroma3.it
}

Received 15 January 2018; Revised 31 July 2018; Accepted 25 September 2018; Published 11 October 2018

Academic Editor: Paola Pellegrini

Copyright (C) 2018 Francesco Bella and Manuel Silvestri. This is an open access article distributed under the Creative Commons Attribution License, which permits unrestricted use, distribution, and reproduction in any medium, provided the original work is properly cited.

\begin{abstract}
The main objective of this study was to assess the effectiveness of several countermeasures at bicycle crossroads on drivers' behavior during the driver-cyclist interaction (a cyclist that crosses the road) by the use of a driving simulator. Three treatments of the cyclist crossroads were investigated: baseline condition (no treatment), raised island, and the colored paved markings. Forty-two participants drove a suburban scenario with several bicycle crossroads having difference configurations and presence/absence of cyclist. Overall, 252 speed profiles were plotted from $150 \mathrm{~m}$ before each crossroad of which 23 showed non-yield events: 12 for the baseline condition, 6 for the colored paved markings, and 5 for the raised island. The method of the survival analysis was applied to model the driver speed reduction time (the elapsed time to pass from the initial speed to the minimum speed during the yielding maneuver) with the use of the Weibull distribution. The model identified the average deceleration, the drivers' age, and the countermeasure condition as significant explanatory variables. The survival curves highlighted that for the colored paved markings the driver adopted longer values of the speed reduction times and then a less aggressive driver's braking behavior. Moreover, the outcomes of the questionnaire confirmed that the colored paved markings were considered to be the most effective in terms of driving aid.
\end{abstract}

\section{Introduction}

The use of the bicycle as viable alternative to the traditional transport systems has continuously increased in the past years as a consequence of the environmental cause, the impact of the pollution on human health, and the cities congestion [e.g., [1-5]]. On the other hand, the data of accidents involving cyclist show that the cyclists are exposed to high risk levels. International statistics $[6,7]$ report that, in 2015, 817 bicyclists were killed in US with an increase of $13 \%$ compared to 2014; moreover, this was the worst result since 1995. Among these fatalities, over 35\% occurred at intersections. European accident statistics also show that $31 \%$ of cyclist fatalities occur at intersections and about $56 \%$ of these fatalities are located at crossroads [8], which represent the crossing of the bicycle paths on the roads. It is well known, in fact, that the driver-cyclist interaction at crossroads is particularly risky [9].

The critical issues of the driver-cyclist interaction at crossroads need to be sought in the driver's behavior and the poor layout of the crossroad, which does not always ensure adequate safety levels for cyclists. For example, a study of Wood et al. [10] found that visibility is the main factor to which cyclists and car drivers attribute crashes involving cyclists. As reported in Kim et al. [11], also the speed is a key factor that contributes to serious and fatal outcomes in vehicle-bicycle accident, while Minikel [12] highlighted that higher vehicles' speed, higher traffic volumes, and the presence of heavy vehicles are detrimental to cyclist safety. Concerning the driver behavior, several studies [e.g., $[13,14]]$ show that the drivers' yielding decision process is mainly affected by the vehicle speed while approaching the intersection.

According to the literature, interactions between vehicles and cyclists at bicycle crossroads are dangerous situations, in which the driver has to be influenced in order to adapt his speed if the cyclist is present, avoiding the occurrence of accidents and improving the cyclist safety.

For these reasons, the objective of this study is analyzing and comparing the driver performance at bicycle crossroads 
in the presence of several countermeasures, which are aimed at allowing the driver to adapt his speed and, thus, improving the ability of the driver to yield to cyclist. The parameter speed reduction time (SRT) was used for the evaluation of the effects on driver performance.

SRT gives a measure of the driver's braking behavior to avoid a potential conflict event at the bicycle crossroad [15, 16]. The speed reduction time is defined as the elapsed time between when the driver reacts to a potential conflict event with a cyclist (by reducing the speed) and when he perceives to have avoided the collision (by yielding to the cyclist) and, thus, ends the deceleration. Therefore, high values of SRT (i.e., longer yielding maneuver times) highlight that the driver receives information timelier and clearer about the possible presence of a cyclist that is crossing at the bicycle crossroad, allowing him to adopt less aggressive braking maneuver.

Two countermeasures were analyzed in the present study: colored paved markings and raised island. The first is a bicycle crossroad provided with a red pavement and its aim is to highlight the presence of the crossroads and focus the attention of the approaching vehicles on it, contributing to the speed reduction [17]. The second is a physical facility in the middle of the road that determines a narrowing of the lane in the last $40 \mathrm{~m}$ in advance of the bicycle crossroad and induces the driver to adapt his speed [18]. Accomplishing these aims was possible by the use of a driving simulator that, mainly, allows risk avoidance for the experimenters and full control of the experimental conditions.

\section{Method}

2.1. Survival Analysis. The survival analysis is based on a probabilistic method which is used to analyze data in the form of time from a well-defined time origin until the occurrence of some particular event of an end point [19]. Such method in the field of the transports is becoming very common and largely used [20-25] and is believed to be the most appropriate tool for the study of the duration variables [26]. Other statistical methods, such as mixed linear models, are restricted in the field of the duration data due to some model assumptions and the unique character of the empirical data (i.e., empirical duration data are limited to have positive values because negative values of time do not exist for definition) [26].

In this study, the speed reduction time (SRT) is the duration variable.

The speed reduction time is a continuous random variable T whose $F(t)$ and $f(t)$ represent the cumulative distribution and the probability density function; the first gives the probability that a driver completes the braking maneuver before some specified time $t$. Conversely, the survivor function $S(t)$ is the probability of a speed reduction time longer than some specified time $t$.

$$
F(t)=\operatorname{Pr}(T<t)=1-\operatorname{Pr}(T \geq t)=1-S(t)
$$

The hazard function $h(t)$ gives the conditional failure rate. More specifically, $h(t)$ is the conditional probability that an event will end between times $t$ and $t+d t$, given that the event has not ended up to time $t$ [27].

$$
h(t)=\lim _{\Delta t \rightarrow 0} \frac{\operatorname{Pr}(t+\Delta t \geq T \geq t \mid T \geq t)}{\Delta t}=\frac{f(t)}{S(t)}
$$

The accelerated failure time (AFT) model was used to model SRT. The AFT model is a parametric approach that allows incorporating the influence of covariates on a hazard function. More specifically, it allows the covariates to accelerate time in a baseline survivor function, which is the survivor function when all covariates are zero [27].

The AFT assumption allows a simple interpretation of results because the estimated parameters quantify the corresponding effect of a covariate on the mean survival time [16].

In the AFT model, the natural logarithm of the duration variables, $\ln (T)$, is expressed as a linear function of explanatory variables, as follows:

$$
\ln (T)=\beta X+\varepsilon
$$

where $X$ is a vector of explanatory variables, $\beta$ is a vector of estimable parameters, and $\varepsilon$ is the error term. Following Washington [20], the survival function in the AFT model assumes the following form:

$$
S(t \mid X)=S_{0}[t \exp (\beta X)]
$$

which leads to the conditional hazard function

$$
h(t \mid X)=h_{0}[t \exp (\beta X)] \exp (\beta X)
$$

where $\mathrm{h}_{\mathrm{o}}$ and $\mathrm{S}_{0}$ are the baseline hazard and the baseline survival function, respectively.

Equations (4) and (5) show the effect of the covariates on the duration variable: the explanatory variables affect directly the duration variable by accelerating or decelerating it.

To estimate the hazard and the survival function in a fully parametric setting, a distribution assumption of the duration variable is needed. Common distribution alternatives include Weibull, lognormal, exponential, gamma, log-logistic, and Gompertz distribution [27]. According to Haque and Washington [16], the Weibull distribution should be selected because it is suitable for modeling data with monotone hazard rates that either increase or decrease with time, which is consistent with the duration variable SRT of the present study. However, a robust comparison among the distribution functions by the information criteria using AIC (Akaike information criterion) [28] and BIC (Bayesian information criterion) [29] was performed to assess the best fitting distribution to model the survival time (see Section 4.2).

2.2. Driving Simulator and Road Scenario. This study was conducted by the use of the interactive fixed-base driving simulator of the Department of Engineering, Roma Tre University. It was previously tested, calibrated, and validated for speed research on two-lane rural roads [30]. This study highlighted that there were no statistically significant differences between the speeds recorded at the driving simulator 


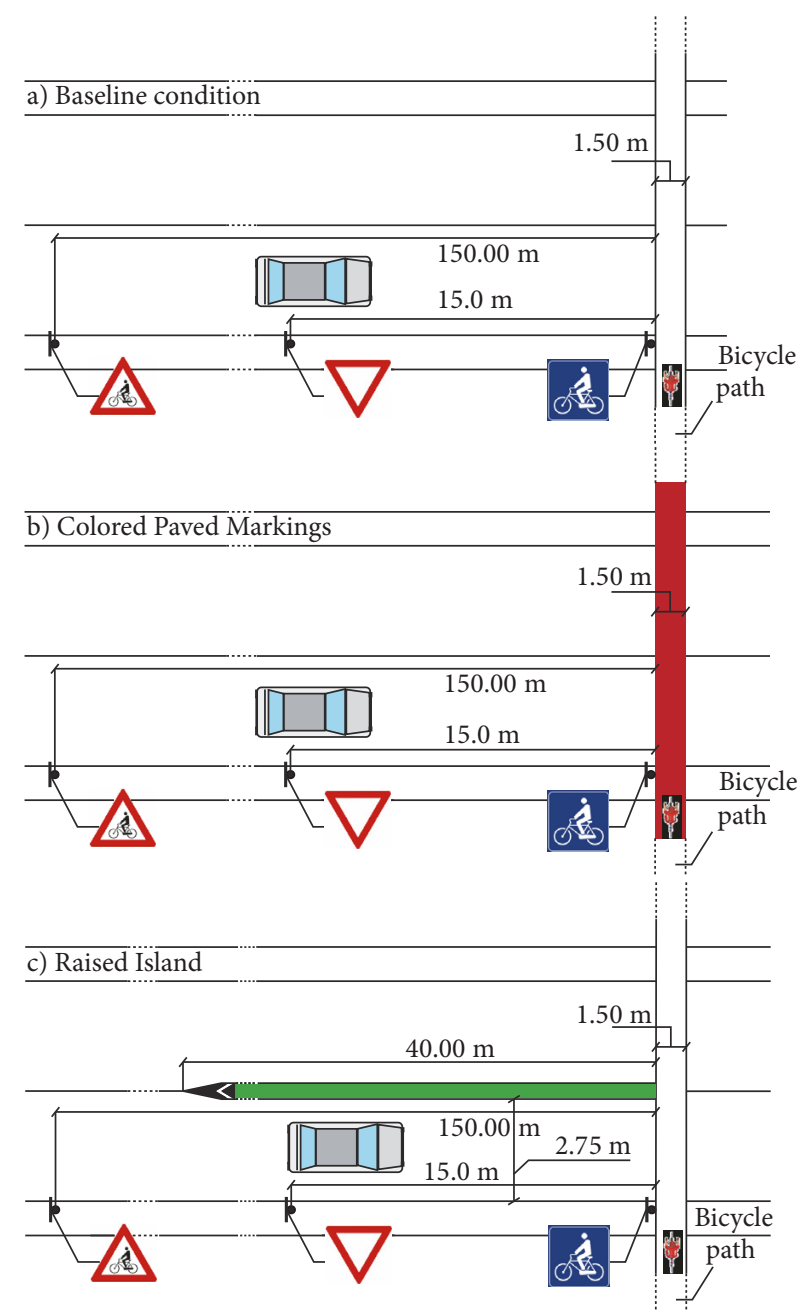

FIGURE 1: (a) Baseline condition; (b) colored paved markings; (c) raised island.

and those recorded on field (absolute validity), except for nondemanding configurations, such as a very long tangent $(1100 \mathrm{~m})$ and a curve with a high radius $(500 \mathrm{~m})$ coming after a long descending tangent. Therefore, the driving simulator of the Department of Engineering, Roma Tre University, is deemed to be a reliable tool for the study of the driver's speed behavior in those road configurations that do not induce high speeds (less than $90 \mathrm{~km} / \mathrm{h}$ ) [e.g., [31-37]].

The hardware interfaces (wheel, pedals, and gear lever) are installed on a real vehicle. The driving scene is projected onto three screens: one in front of the vehicle and one on either side, which provide a $135^{\circ}$ field of view. The resolution of the visual scene is $1024 \times 768$ pixels with a refresh rate of 30 to $60 \mathrm{~Hz}$. The system is also equipped with a sound system that reproduces the sounds of the engine.

The experimental road scenario was a two-lane suburban road about $7.6 \mathrm{Km}$ long in which also the cyclist that crosses the road was simulated. Nine bicycle crossroads ( 3 for each of the 3 types described in the following) were present along the alignment. To ensure the same approaching condition, a signalized intersection was placed in advance of each bicycle crossroad.
Each driver was obligated to stop at the signalized intersection, due to the red light that turned on when the driver was at approximately $100 \mathrm{~m}$ from the intersection. The distance between the signalized intersection and bicycle crossroad was equal to $400 \mathrm{~m}$, which allowed the drivers to reach a congruous speed for the simulated scenario. The posted speed limit was $50 \mathrm{Km} / \mathrm{h}$ while the cross-section was $10 \mathrm{~m}$ wide, formed by two $3.00 \mathrm{~m}$ wide lanes, two paved shoulders $0.50 \mathrm{~m}$ wide, and two curbs $1.50 \mathrm{~m}$ wide, according to the Italian road design guidelines [38]. According to the Italian Highway Code [39] the bicycle crossroad was $1.50 \mathrm{~m}$ wide and three vertical signs were posted: one at $150 \mathrm{~m}$ in advance of the bicycle crossroad to signal the presence of it, one at $10 \mathrm{~m}$, to advise the driver to yield if the cyclist was present, and one in correspondence to the bicycle crossroad. This configuration represents the baseline condition (Figure 1(a)). In addition to the baseline condition, two types of countermeasures were placed in the scenario: colored paved markings and raised island. The first was the red painting of the bicycle crossroad (Figure 1(b)), while the second was a physical facility $40 \mathrm{~m}$ long, $0.50 \mathrm{~m}$ wide, and $0.05 \mathrm{~m}$ high (Figure $1(\mathrm{c})$ ), which causes the narrowing of the 


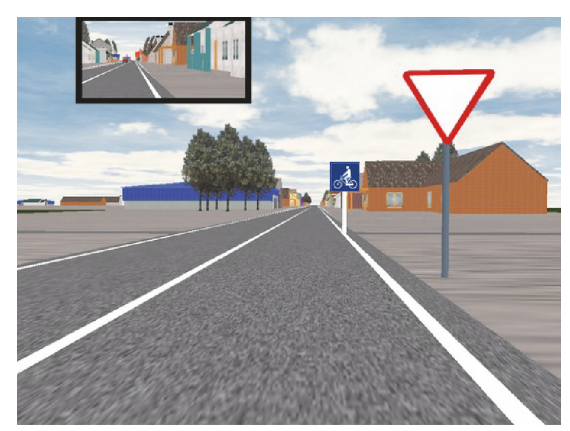

(a)

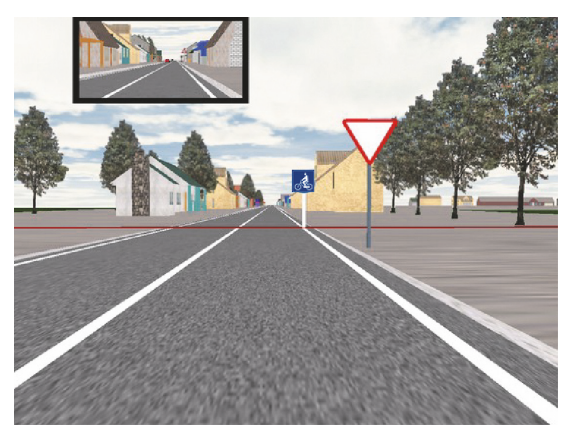

(b)

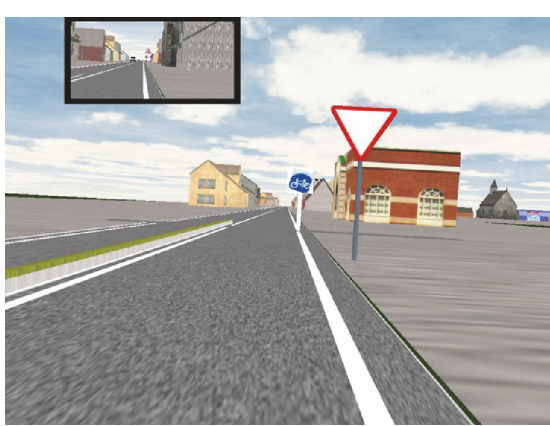

(c)

FIGURE 2: Bicycle crossroads as seen by drivers during the experiment: (a) baseline condition; (b) colored paved markings; (c) raised island.

vehicle lane to $2.75 \mathrm{~m}$ in the last $40 \mathrm{~m}$ in advance of the bicycle crossroad.

Figure 2 shows examples of bicycle crossroads as seen by drivers during the experiment.

At six bicycle crossroads ( 2 for the baseline condition, 2 for the colored paved markings, and 2 for the raised island) a cyclist coming from driver right side crossed the road. The cyclist was set to start the crossing at $20 \mathrm{~m}$ from the collision point when the driver was at $50 \mathrm{~m}$ from it. The speed of the cyclist was $20 \mathrm{Km} / \mathrm{h}$. Assuming the driver speed equal to $50 \mathrm{Km} / \mathrm{h}$, in such condition the driver and cyclist have the same time to arrive (3.6 s) to the collision point. It should be noted that this condition is representative of a theoretical driver-cyclist interaction, which occurs only if the driver adopts the hypothesized speed value.

To avoid a potential effect of the order on the driver's behavior, 3 road scenarios that have a different sequence of the 9 combinations of bicycle crossroad (baseline condition, colored paved markings, and raised island) $\mathrm{x}$ cyclist (cyclist absence and two conditions in which the cyclist was crossing the road) were implemented in the driving simulator. The participants were divided into 3 groups and each group was assigned to only one road scenario (see next section on participants). Thus, each group experienced a different presentation sequence of the 9 combinations of crossroad layout $\mathrm{x}$ cyclist condition.

For the analysis of the present study, only the conditions in which the cyclist was present were used (6 combinations: 3 countermeasures $\mathrm{x} 2$ cyclist conditions presence).

2.3. Procedure and Participants. The driver did not experience interaction with other vehicles in their driving lane. On the opposing lane, a slight amount of traffic was present to induce the driver not to drift to the incoming traffic lane. The simulated vehicle was a standard medium-class car with automatic gears. The data recording system acquired all of the parameters at spatial intervals of $2 \mathrm{~m}$. The experiment procedure consisted of the following steps: (a) communicating to the driver about the duration of the driving and the use of the simulated vehicle tools; (b) training at the driving simulator on a specific alignment with a length of approximately 5 $\mathrm{Km}$ to become familiar with the steering wheel, accelerator, and brake pedal; (c) filling in a form with personal data, years of driving experience, and average annual distance driven; (d) driving one of the three road scenarios with a specific bicycle crossroads-cyclist sequence; (e) filling in a questionnaire about the discomfort that is perceived during driving, to eliminate from the sample driving performed under anomalous conditions. This questionnaire consisted of 5 questions, in which each question addressed a type of discomfort: nausea, giddiness, daze, fatigue, and other. A score from 1 to 4 in proportion to the level of discomfort experienced could be selected: null, light, medium, and high. The null and light level for all four types of discomfort are considered to be the acceptable condition for driving; (f) filling in a questionnaire about how the driver perceived the countermeasures. For this question, the participant could choose between (a) driving aid and (b) obstacle; for each of them, the driver could answer by a score from 0 to 3 in proportion to the perceived effectiveness. Drivers were instructed to drive as they normally would in the real world.

Forty-two drivers (24 men and 18 women), whose ages ranged from 24 to 59 (mean $=29.3 ; \mathrm{SD}=8.5$ ) and who had regular European driving licenses for at least three years ( mean $=11.0 ; \mathrm{SD}=8.0$ ), were selected to perform the driving in the simulator. The participants were chosen from students, faculty, and staff of the University and volunteers from outside of the University. The drivers had no prior experience with the driving simulator and had an average annual driven distance of at least $2500 \mathrm{~km}$. According to the questionnaire on perceived discomfort, no participant was excluded from the analysis due to the perceived discomfort. Thus, the sample used for the analysis consisted of all 42 drivers, which were divided into 3 groups; the 3 groups drove different scenarios, which were characterized by a specific sequence of bicycle crossroad/cyclist.

\section{Data Processing}

To obtain the explanatory variables of the driver behavior, for each participant and for each configuration of the bicycle crossroad, the speed profile of the last $150 \mathrm{~m}$ in advance of the bicycle crossroad was plotted. Overall, 252 speed profiles were obtained from the driving tests (42 participants x 6 bicycle crossroads). The following variables were determined from each speed profile: 
(i) $\mathrm{V}_{\mathrm{i}}$ : initial speed, which is the speed identified at the moment when the driver starts to decrease his speed, in response to the cyclist that is crossing

(ii) $\mathrm{L}_{\mathrm{Vi}}$ : initial speed distance, which is the distance from the bicycle crossroad where $\mathrm{V}_{\mathrm{i}}$ is recorded

(iii) $\mathrm{V}_{\mathrm{m}}$ : minimum speed, which is the minimum value of the speed during the driver braking maneuver

(iv) $\mathrm{L}_{\mathrm{Vm}}$ : minimum speed distance, which is the distance from the bicycle crossroad where $\mathrm{V}_{\mathrm{m}}$ is recorded

(v) $d_{a v}$ : average deceleration, which is the average deceleration adopted by the driver during the entire braking maneuver obtained from

$$
d_{a v}=\frac{\left(V_{i}^{2}-V_{m}^{2}\right)}{2\left(L_{V i}-L_{V \min }\right)}
$$

(vi) SRT: speed reduction time, which is the elapsed time to pass from the initial speed to the minimum speed.

Table 1 reports the mean values and the standard deviation of the variables obtained from the speed profiles. The speed profiles also highlighted several events in which the driver did not yield to the cyclist. More specifically, 12 failed yields were recorded for the baseline condition, 6 for the colored paved markings, and 5 for the raised island. These cases were excluded from the analysis due to the missed driver-cyclist interaction at the bicycle crossroad. This event was due to the high speed adopted by the driver which passed, thus, the conflict point before the cyclist.

Thus, a total of 229 observations of the driver braking behavior were used for the analysis.

\section{Data Analysis}

4.1. Multicollinearity Analysis for the Independent Variables Selection of the Survival Model. For a reliable modeling of the speed reduction time, a Pearson's product-moment correlation (PPMC) analysis was performed (Table 2). The aim was the detecting of multicollinearity among the potential explicative variables (the dynamic variables $\mathrm{V}_{\mathrm{i}}, \mathrm{V}_{\text {min }}, \mathrm{L}_{\mathrm{Vi}}$, $\mathrm{LV}_{\min } \mathrm{d}_{\mathrm{av}}$, the drivers' age, and the drivers' gender).

The outcomes of the PPMC analysis are reported too. The analysis showed that there were a moderate positive correlation between $\mathrm{Lv}_{\mathrm{i}}$ and $\mathrm{d}_{\mathrm{av}}, \mathrm{r}(227)=0.393, \mathrm{p}<0.001$ and between $\mathrm{L}_{\mathrm{Vmin}}$ and $\mathrm{d}_{\mathrm{av}}, \mathrm{r}(227)=0.230, \mathrm{p}<0.02$ and $\mathrm{a}$ strong positive correlation between $\mathrm{V}_{\text {min }}$ and $\mathrm{d}_{\mathrm{av}}, \mathrm{r}(227)=$ $0.407, \mathrm{p}<0.001$. Results showed also that there was a strong negative correlation between $\mathrm{V}_{\mathrm{i}}$ and $\mathrm{d}_{\mathrm{av}}, \mathrm{r}(227)=-0.429$, $\mathrm{p}<0.001$. Moreover, the PPMC analysis revealed that there was a moderate negative correlation between $\mathrm{V}_{\mathrm{i}}$ and $\mathrm{L}_{\mathrm{Vi}}, \mathrm{r}$ $(227)=-0.254, \mathrm{p}<0.001$ and a strong negative correlation between $\mathrm{V}_{\mathrm{i}}$ and $\mathrm{L}_{\mathrm{Vmin}}, \mathrm{r}(227)=-0.474, \mathrm{p}<0.001$. Finally, there was a moderate positive correlation between $\mathrm{V}_{\mathrm{i}}$ and $\mathrm{V}_{\min }, \mathrm{r}$ $(227)=0.290, \mathrm{p}<0.001$.

Finally, there was a strong positive correlation between $\mathrm{L}_{\mathrm{Vmin}}$ and $\mathrm{L}_{\mathrm{Vi}}, \mathrm{r}(227)=0.822, \mathrm{p}<0.001$ and a moderate positive correlation between $\mathrm{V}_{\min }$ and $\mathrm{L}_{\mathrm{Vi}}, \mathrm{r}(227)=0.213$, $\mathrm{p}<0.05$.
Therefore, considering the outcomes of the PPMC analysis, only the dynamic variable average deceleration $\mathrm{d}_{\mathrm{av}}$ was used as explanatory variable due to the high representativeness of the driver's braking behavior provided by this variable. The other dynamic variables $\mathrm{V}_{\mathrm{i}}, \mathrm{L}_{\mathrm{Vi}}, \mathrm{V}_{\text {min }}$, and $\mathrm{L}_{\mathrm{Vmin}}$ were correlated in a statistically significant way with the average deceleration and, thus, were excluded from the model to avoid multicollinearity, ensuring the reliability of the model and the statistical significance of the independent variables [40].

Finally, the PPMC analysis showed that there was no correlation between the average deceleration and the drivers' age, $\mathrm{r}(227)=-0.059, \mathrm{p}>0.10$ and the drivers' gender, $\mathrm{r}(227)=$ $0.068, \mathrm{p}>0.10$.

Therefore, to model the drivers' speed reduction time, the continuous variables, driver's average deceleration (mean value and standard deviation were $2.67 \mathrm{~m} / \mathrm{s}^{2}$ and $1.60 \mathrm{~m} / \mathrm{s}^{2}$, respectively), drivers' age (mean value was equal to 29.3 years and the standard deviation was 8.5 years), and the categorical or indicator variables countermeasure and drivers' gender, were used.

4.2. Assessment of the Best Fitting Survival Function Distribution. The distribution of the survival function was selected comparing AIC (Akaike information criterion) and BIC (Bayesian information criterion). Table 3 shows the values of AIC and BIC for the Weibull, lognormal, exponential, log-logistic, and the gamma distribution functions. All the models with different survival function distributions were compared using the same set of variables.

Considering the values of AIC and BIC, the distribution for the selected survival function to model the SRT was the Weibull function.

The hazard function of the Weibull duration model is expressed as

$$
h(t)=(\lambda P)(\lambda t)^{P-1}
$$

and the survival function of the Weibull duration model is expressed as

$$
S(t)=\exp \left(-\lambda t^{P}\right)
$$

where $\lambda$ and $\mathrm{P}$ are the location and the scale parameter, respectively. A positive value of the scale parameter $\mathrm{P}$ means that the survival probability of the duration variable $(\mathrm{S}(\mathrm{t})$ ) decreases with the elapsed time.

The location parameter, with the introduction of explanatory variables, has the following expression:

$$
\lambda=\exp \left[-P\left(\beta_{0}+\beta_{1} X_{1}+\cdots\right)\right]
$$

where each $\beta_{\mathrm{i}}$ represents the coefficient of the explanatory variable $\mathrm{X}_{\mathrm{i}}$. The final expression of the survival function of the Weibull duration model is the following:

$$
S(t)=\exp \left\{-\exp \left[-P\left(\beta_{0}+\beta_{1} X_{1}+\cdots\right)\right] t^{P}\right\}
$$

The exponential value of each explanatory variable coefficient $\left(\exp \left(\beta_{\mathrm{i}}\right)\right)$ provides an easy and meaningful interpretation about the impact on the duration variable due to an increase or a decrease of the independent variable $\left(\mathrm{X}_{\mathrm{i}}\right)$. 


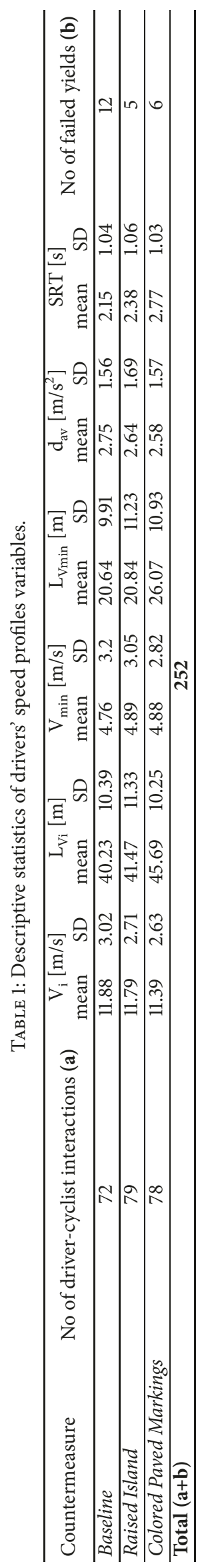


TABLE 2: Results of Pearson's product-moment correlation analysis.

\begin{tabular}{|c|c|c|c|c|c|c|c|}
\hline Variable & $\mathrm{V}_{\mathrm{i}}$ & $\mathrm{L}_{\mathrm{Vi}}$ & $\mathrm{V}_{\min }$ & $\mathrm{L}_{\mathrm{V} \min }$ & $\mathrm{d}_{\mathrm{av}}$ & driver's age & driver's gender \\
\hline $\mathrm{V}_{\mathrm{i}}$ & - & & & & & & \\
\hline $\mathrm{L}_{\mathrm{Vi}}$ & $-0.254 *$ & - & & & & & \\
\hline $\mathrm{V}_{\text {min }}$ & $0.290 *$ & $0.213 * * *$ & - & & & & \\
\hline $\mathrm{L}_{\mathrm{Vmin}}$ & $-0.474 *$ & $0.822 *$ & -0.044 & - & & & \\
\hline $\mathrm{d}_{\mathrm{av}}$ & $-0.429 *$ & $0.393 *$ & $0.407 *$ & $0.230 * *$ & - & & \\
\hline driver's age & -0.057 & 0.013 & $0.908 *$ & 0.013 & -0.059 & - & \\
\hline driver's gender & -0.003 & 0.022 & $0.240 * *$ & -0.017 & 0.068 & -0.119 & - \\
\hline
\end{tabular}

$*$ : correlation is significant at the 0.001 level, two-tailed test

$* *$ : correlation is significant at 0.02 level, two-tailed test

$* * *$ : correlation is significant at 0.05 level, two-tailed test.

TABLE 3: Summary of information criteria results.

\begin{tabular}{lcc}
\hline Survival function distribution & AIC & BIC \\
\hline Weibull & 222.07 & 245.63 \\
\hline lognormal & 284.51 & 311.44 \\
\hline exponential & Convergence not achieved & Convergence not achieved \\
\hline Log-logistic & 244.54 & 271.46 \\
\hline gamma & Convergence not achieved & Convergence not achieved \\
\hline
\end{tabular}

In addition, three models based on the Weibull distribution were also tested with different combination of the independent variables and compared with the information criteria. In the table (Table 4) the outcomes of the comparison are reported.

Table 4 shows that the lowest values of AIC, BIC, and log-likelihood (LL) were recorded for model III, in which the categorical variable countermeasure and the continuous variables average deceleration and drivers' age were included. Moreover, the variable driver's gender was not statistically significant $(\mathrm{P}=0.983)$ and, thus, was excluded from the model.

\section{Results}

The application of the duration model as specified in Section 4.2 implies that the individual observations are independent. In the present study, data were collected from a repeated measures experiment. Therefore, the observations might be subjected to individual level of heterogeneity or frailty, which implies that data from an individual might be correlated [16]. Without accounting for shared frailty or heterogeneities and potential correlations, the duration model would suffer from a specification error that could lead to erroneous inferences on the shape of the hazard function. In addition, the standard error estimates of the regression parameters might be underestimated and inferences from the estimated model might be misleading [16]. To avoid potential estimating errors, two extensions of the AFT model were tested: Weibull regression model with clustered heterogeneity and Weibull regression model with shared frailty.

The first model fits the standard duration model and then adjusts the standard error estimates to account for the possible correlations induced by the repeated observations within individuals $[41,42]$.

Weibull regression model with shared frailty allows taking into account the correlation among observations obtained from the same driver and maintains independence among observations across different drivers.

The shared frailty model can be expressed by modifying the conditional hazard function (see (5)) as follows:

$$
h_{i j}\left(t \mid \alpha_{i}\right)=\alpha_{i} h_{i j}(t)=\alpha_{i} h_{0}\left[t \exp \left(\beta X_{i j}\right)\right] \exp \left(\beta X_{i j}\right)
$$

where $h_{i j}$ is the hazard function for the $i_{\text {th }}$ driver in the $j_{\text {th }}$ driving test and $\alpha_{i}$ is the shared frailty, which is assumed to be gamma or inverse-Gaussian distributed, with mean 1 and variance $\theta$.

Weibull regression model with clustered heterogeneity and Weibull regression model with shared frailty were then compared by the likelihood ratio statistics [27], the Akaike information criteria (AIC), and the Bayesian information criteria (BIC) to identify the best fitting model. To determine the effects of explanatory variables, the exponents of the coefficients were calculated. The exponent of a coefficient provides an intuitive way of interpreting the results by translating to a percent change in the survival duration variable resulting from a unit increase for continuous explanatory variables and a change from zero to one for categorical or indicator variables [16].

The development of the Weibull accelerated failure time (AFT) for the speed reduction times (SRT) was carried out using the statistical software STATA version 14.1. After the selection of the best fit distribution and the significant independent variables, the Weibull AFT model with clustered heterogeneity and the Weibull AFT model with shared frailty were tested. The frailty was gamma-distributed. The two models were compared with their likelihood ratio statistics 
TABLE 4: Summary of information criteria comparison of three Weibull regression models.

\begin{tabular}{|c|c|c|c|c|}
\hline Model & Independent variables & AIC & $\mathrm{BIC}$ & Log - Likelihood (LL) \\
\hline$I$ & $\begin{array}{c}\text { Countermeasure } \\
\mathrm{d}_{\mathrm{av}}\end{array}$ & 225.39 & 245.98 & -106.63 \\
\hline II & $\begin{array}{c}\text { Countermeasure } \\
\mathrm{d}_{\mathrm{av}} \\
\text { Driver's gender }\end{array}$ & 227.25 & 250.83 & -106.64 \\
\hline III & $\begin{array}{c}\text { Countermeasure } \\
\mathrm{d}_{\mathrm{av}} \\
\text { Driver's age }\end{array}$ & 222.07 & 245.63 & -104.04 \\
\hline
\end{tabular}

TABLE 5: Estimates of the Weibull AFT model with clustered heterogeneity for SRT.

\begin{tabular}{|c|c|c|c|c|c|c|c|}
\hline \multirow{2}{*}{$\frac{\text { Variable }}{\mathrm{d}_{\mathrm{av}}\left[\mathrm{m} / \mathrm{s}^{2}\right]}$} & \multirow{2}{*}{$\begin{array}{c}\text { Estimate } \\
-0.142\end{array}$} & \multirow{2}{*}{$\begin{array}{c}\text { SE } \\
0.018\end{array}$} & \multirow{2}{*}{$\begin{array}{c}z-\text { Statistic } \\
-7.85\end{array}$} & \multirow{2}{*}{$\frac{p \text {-value }}{0.000}$} & \multirow{2}{*}{$\frac{\operatorname{Exp}(\beta)}{0.867}$} & \multicolumn{2}{|c|}{$95 \%$ Conf. Interval } \\
\hline & & & & & & -0.176 & -0.107 \\
\hline Drivers' age [years] & 0.006 & 0.003 & -2.15 & 0.031 & 1.006 & 0.001 & 0.012 \\
\hline \multicolumn{8}{|l|}{ Countermeasure } \\
\hline Baseline condition & - & - & - & - & - & - & - \\
\hline Raised island & 0.052 & 0.061 & 0.85 & 0.349 & 1.053 & -0.067 & 0.171 \\
\hline Colored paved markings & 0.211 & 0.059 & 3.53 & 0.000 & 1.235 & 0.094 & 0.328 \\
\hline Constant & 1.432 & 0.127 & 11.30 & 0.000 & & 1.184 & 1.681 \\
\hline $\mathrm{P}$ & 3.166 & 0.307 & & & & 2.618 & 3.829 \\
\hline Log-likelihood at convergence (Pseudo) & -104.04 & & & & & & \\
\hline Log-likelihood at zero & -138.11 & & & & & & \\
\hline AIC & 222.07 & & & & & & \\
\hline $\mathrm{BIC}$ & 245.63 & & & & & & \\
\hline No of observations & 229 & & & & & & \\
\hline No of groups & 42 & & & & & & \\
\hline
\end{tabular}

and with the AIC and BIC tests. The likelihood ratio statistic of the Weibull AFT model with clustered heterogeneity was -104.04 while that for the shared frailty model was 104.54, highlighting that the first was preferable. The AIC and BIC tests also confirmed the better fit of the model; for the clustered heterogeneity model and for the shared frailty model the AICs were 222.07 and 223.08, while BICs were 245.63 and 246.65 , respectively. Thus, comparing the likelihood ratio statistics, AIC and BIC, the Weibull AFT model with clustered heterogeneity was the preferable option for modeling the speed reduction times of the drivers in response to a cyclist that is crossing at the bicycle crossroad, under different conditions of safety measures.

Table 5 shows the significant parameter estimates for the Weibull AFT model with clustered heterogeneity for SRT. The value of the scale parameter $\mathrm{P}$ is equal to 3.166 , meaning that the survival probability of SRT decreased with the elapsed time. For example, on average the probability of completing the yielding maneuver after $5 \mathrm{~s}$ was 7.3 times higher than that after $2 \mathrm{~s}$ (i.e., $(5 / 2)^{3166-1}$ ). The scale parameter $\mathrm{P}$ higher than 1 implies that the hazard function of the speed reduction times was monotone and with positive duration dependence; this is consistent with the hypothesis of the applied model.

The model identified that the driver average deceleration $\left(d_{a v}\right)$ was statistically significant $(P=0.000)$ for the drivers' speed reduction times. The coefficient of the average deceleration was negative, which implies that when the value of this variable increased, the SRT value decreased. More specifically, for a $1 \mathrm{~m} / \mathrm{s}^{2}$ increase of the driver's average deceleration, the time required to complete the yielding maneuver was approximately $13 \%$ lower $(\exp (\beta)=0.867)$. Moreover, the model identified the drivers' age as significant explanatory variable $(\mathrm{P}=0.031)$ : more specifically, for an increase of one year in driver's age, SRT was approximately $1 \%$ longer $(\exp (\beta)=1.006)$.

Among the countermeasure conditions, the model identified significant coefficient estimates for the colored paved markings $(\mathrm{P}=0.000)$ while for the raised island the effect on the survival model was not statistically significant $(\mathrm{P}=0.349)$. For the coefficient estimate of the baseline condition the model did not provide a coefficient estimate, because this condition was set by the model as the reference one.

The pairwise comparison with Bonferroni's correction showed that, for the baseline condition and the raised island, the values of SRT (equal to 4.76 and 5.01s for null survival probability, respectively) were statistically significantly shorter than that for the colored paved markings $(5.88 \mathrm{~s}$; mean difference $=1.12 \mathrm{~s}, \mathrm{P}=0.001$; mean difference $=0.87 \mathrm{~s}$, $\mathrm{P}=0.006$, respectively). More specifically, for the colored paved markings, the SRT was $23.5 \%$ longer than that for the baseline condition $(\exp (\beta)=1.235)$ while for the raised island SRT was 5.3\% longer than that for the baseline condition $(\exp (\beta)=1.053)$. However, this difference was not statistically significant. 


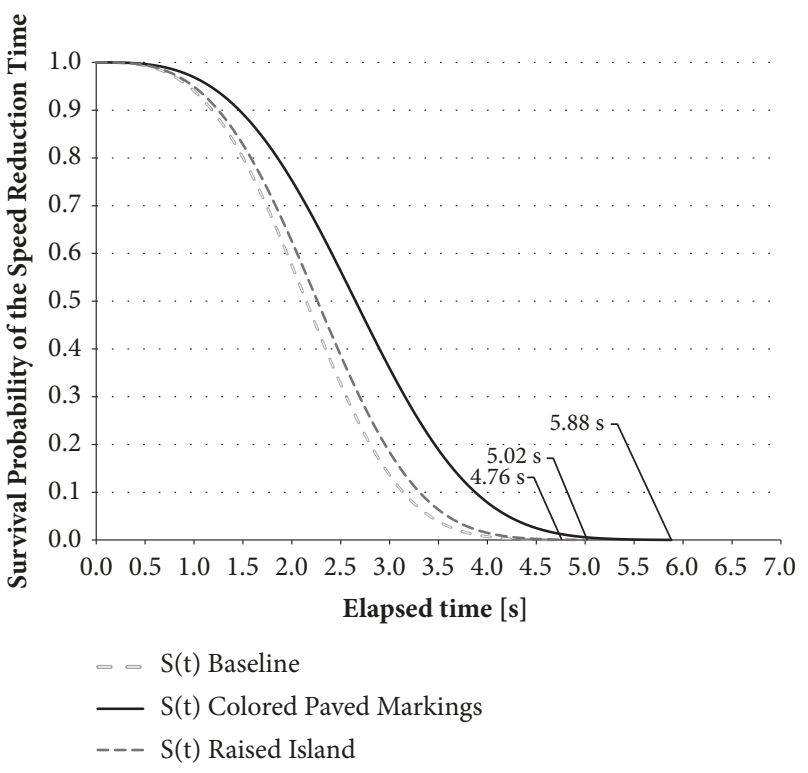

FIGURE 3: Survival curves of SRT.
The use of the Weibull AFT model with clustered heterogeneity allowed a comparison of the driver's speed reduction time for the yielding maneuver, under different configurations of the bicycle crossroad. The representation of the drivers' speed reduction patterns was possible by plotting the survival curves with the use of the estimated coefficients of the average deceleration and the countermeasures condition.

The estimation of the survival curves was provided by (10), where the vector $\mathrm{X}$ represents the explanatory variables of the drivers' speed reduction time, while the vector $\beta$ represents the related coefficients estimated by the Weibull AFT model. The survival curves were plotted by using the mean values of the continuous variables: average deceleration (2.67 $\mathrm{m} / \mathrm{s}^{2}$ ), drivers' age (29.3 years), and the estimated coefficients of the average deceleration, driver's age, and countermeasure conditions in Table 5. For example, the survival probability of SRT for the raised island and the colored paved markings after $1.5 \mathrm{~s}$ was, respectively,

$$
\begin{aligned}
& S(t=1.5)=\exp \left\{-[\exp (3.166(1.432+(-0.142 \cdot 2.67)+(-0.006 \cdot 29.3)+(0.052)))] \cdot 1.5^{3.166}\right\} \\
& S(t=1.5)=\exp \left\{-[\exp (3.166(1.432+(-0.142 \cdot 2.67)+(-0.006 \cdot 29.3)+(0.211)))] \cdot 1.5^{3.166}\right\}
\end{aligned}
$$

Using this method, the survival curve for each countermeasure (baseline condition, raised island, and colored paved markings) was plotted (Figure 3).

\section{Outcomes of the Questionnaire on the Effectiveness of the Countermeasures}

The results of the questionnaire showed that $71 \%$ of the drivers (30 of 42) reported the highest score of "driving aid" for the colored paved markings, while only $19 \%$ of the drivers (8 of 42) reported the same score of "driving aid" for the raised island. For the baseline condition, the highest score of "driving aid" was reported by $40 \%$ of the drivers (17 of 42 ). Consistently with this outcome, $79 \%$ (33 of 42) of the drivers reported the lower score of the "obstacle driving effect" for the colored paved markings, while only $31 \%$ (13 of 42) of the drivers reported the lower score of the "obstacle driving effect" for the raised island. For the baseline condition, the lower score of the "obstacle driving effect" was reported by $76 \%$ of drivers (32 of 42 ).

\section{Discussion}

As expected, the survival probability for the speed reduction time during the yielding maneuver in response to a cyclist that is crossing decreases with the elapsed time (Figure 3). This means that the probabilities that the driver completes the speed decreasing maneuver to avoid the collision increase with the elapsed time.

The survival curves for different countermeasure conditions show that, for a fixed value of the elapsed time, the higher survival probability of SRT was obtained for the colored paved markings while the lower survival probability of SRT was obtained for the baseline condition. For example, after 2.5 seconds, the speed reduction time survival probability for colored paved markings was about $56 \%$, while for raised island and the baseline condition it was approximately $39 \%$ and $33 \%$, respectively.

The event duration, that is, the speed reduction time (obtained for null value of the survival probability), was 5.88s for the colored paved markings, while it was $1.12 \mathrm{~s}$ shorter (statistically significant) for the baseline condition (4.76s) and $0.86 \mathrm{~s}$ shorter (statistically significant) for the raised island (5.02s).

Overall, the outcomes of the Weibull AFT model highlight that when the bicycle crossing was reorganized with the colored paved markings, the driver adopted more time to complete the braking maneuver.

It should be noted that speed reduction time values represent different times of yielding maneuvers in response to a cyclist that is crossing the road. This means that longer values of the speed reduction times are linked to smoother yielding maneuver. The results of the Weibull AFT model showed that, for the colored paved markings, the longer time to pass from the initial speed to the minimum speed 
was required. This finding suggests that, in this condition of bicycle crossroad, the drivers are able to advance the yielding maneuver and the consequence is that they adopt a less aggressive braking behavior.

This result can reasonably be due to a better visibility of the bicycle crossing, which effectively gained the driver's attention allowing him to adopt a less abrupt maneuver. This aim is consistent with previous results of Bella and Silvestri $[43,44]$, which highlighted that the presence of the colored paved markings at the bicycle crossroads allowed the advance of the driver braking maneuver. It is also in line with the study of Leden at al. [45], which reported that the presence of a raised bicycle crossing provided with a colored pavement can affect the driver's visual search and probably his expectation, ensuring higher cyclist safety levels.

Consistently with the improvement of the driver performance, also an increase of the trend of the yielding behavior was recorded for the colored paved markings. For this countermeasure, the driver did not yield in $7.1 \%$ (6 of 84) of the interactions with the cyclist, while for the baseline condition the failed yielding rate was the $14.3 \%$ (12 of 84 ) (Table 1). The observed results were consistent with those obtained by Hallmark et al. [17] and by Iasmin et al. [46], which found that the presence of the colored paving at the crossroads led to an increase of the yielding probability.

The Weibull AFT showed also a slightly positive effect of the raised island on SRT compared with the baseline condition, but not as effective as that for the colored paved markings.

Finally, the drivers' SRT was affected in a statistically significant way by the average deceleration $\mathrm{d}_{\mathrm{av}}$ and the driver's age. More specifically the average deceleration was negatively associated with SRT. This result was expected because if the driver acts a more abrupt deceleration he needs less time to pass from the initial speed $V_{i}$ to the minimum speed $V_{m}$. On the contrary, the driver's age was positively associated with SRT, meaning that with the increasing of the driver's age an increase of SRT was expected. Considering the fact that the higher the SRT, the smoother the driver's braking behavior to yield to the cyclist, this result highlights that older drivers are expected to adopt less abrupt yielding maneuver compared to younger drivers. This finding was consistent with previous studies [47-49], in which the correlation analysis proved that the driver's age has a statistically significant negative correlation with the aggressive driving behavior.

\section{Conclusions}

The present study aimed at the investigation of how the reorganization with safety countermeasures of the bicycle crossroads affects the drivers' braking behavior in response to a cyclist that crosses the road. The safety countermeasures implemented in the driving simulator scenario were the raised island and the colored paved markings. The drivers' SRT (the elapsed time to pass from the initial speed $V_{i}$ to the minimum speed $V_{m}$ during the yielding maneuver) was the variable used to analyze the driver braking behavior.

The analysis was carried out by the Weibull AFT duration model, which identified the average deceleration $d_{a v}$, the drivers' age, and the countermeasure condition as explanatory variables that affected the speed reduction time in a statistically significant way. The average deceleration affected negatively SRT, implying that aggressive driving behaviors (i.e., higher deceleration rates) correspond to shorter times to pass from the initial speed to the minimum speed. The driver's age, instead, was positively associated with SRT; specifically, the model shows that older drivers undertake lower deceleration rates and, thus, smoother yielding maneuver. The plot of SRT survival curves for each countermeasure highlighted that the time taken by the driver to reduce the speed during the yielding maneuver was longer (statistically significant) when the colored pavement was present compared to the baseline condition and the raised island. Lastly, a slight effect on drivers' SRT was also recorded compared to the baseline condition but it was not significant.

The better visibility of the bicycle crossroad provided by the presence of the colored paving allowed the driver to adopt smoother braking maneuver to yield to the cyclist. It should be also noted that the benefits of a less aggressive brake can lead to a decrease of the probability that a rear-end collision occurs.

The increase of the cyclist safety provided by the colored paved markings was also highlighted by the low number of events in which the driver did not yield compared to that recorded for the baseline condition. Finally, the effectiveness of this countermeasure was also confirmed by the outcomes of the questionnaire, which revealed that $71 \%$ of drivers reported the highest score for driving aid when the bicycle crossroad was provided with the colored pavement.

The experiment of the present study was carried out by the use of the driving simulator of the Roma TRE University, Department of Engineering. Therefore, the caveats that usually referred to driving simulator studies must be raised. Among these, the main one referred to the possibility that the driving tests can result in a drivers' behavior that is different from the actual behavior in the real world.

The driving simulator used in the present study was previously validated for the study of the drivers' behavior on two-lane rural world [31]. That study assessed the numerical correspondence between the speed data recorded in the driving simulator and those recorded in the real world (absolute validity) for those road configurations that do not induce high speeds (less than $90 \mathrm{~km} / \mathrm{h}$, which are recorded in the present study). However, the obtained results cannot be generalized because of concerns about validation of the simulator for different experiment and road types [31]. A rigorous validation study of the driving simulator that compares the drivers' behavior at bicycle crossroads recorded at the simulation and that obtained in the real world has not been yet developed.

However, for the objective of the present experiment (comparing the driver performance at bicycle crossroads in the presence of several countermeasures, without the claim to provide valuations in absolute terms of the driver behavior), only the relative validity (which refers to the correspondence between the effects of different variations in the driving situation) is required [50]. Considering this point, it should be noted that 
(i) the obtained results in the present study are in line with those recorded in fields studies by Leden et al. [45], Hallmark et al. [17], and Iasmin et al. [46]

(ii) the recorded data showed that the drivers reacted differently at the different crossroad layouts and cyclist condition, giving reasonable results

In addition, the results based on the drivers' behavior recorded during the simulations were fully confirmed by the subjective ratings acquired through the questionnaire about the effectiveness of the countermeasures.

In light of this, the obtained results can be considered as reliable in terms of relative effects induced by countermeasures and cyclist condition on the driver's behavior during the interaction with a cyclist that crosses the road.

\section{Data Availability}

The data used to support the findings of this study are available from the corresponding author upon request.

\section{Conflicts of Interest}

The authors declare that they have no conflicts of interest.

\section{Acknowledgments}

This research was financially supported by the Italian Ministry of Education, Research and Universities.

\section{References}

[1] E. Heinen, B. van Wee, and K. Maat, "Commuting by bicycle: An overview of the literature," Transport Reviews, vol. 30, no. 1, pp. 59-96, 2010.

[2] Health Organization Development of methods for quantification of health benefits from walking and cycling. 2014. http://www.euro.who.int/en/health-topics/disease-prevention/ /physical-activity/activities/hepa-europe/hepa-europeprojects-and-working-groups/development-of-methods-forquantification-of-health-benefits-from-walking-and-cycling.

[3] L. S. Fruhen and R. Flin, "Car driver attitudes, perceptions of social norms and aggressive driving behaviour towards cyclists," Accident Analysis \& Prevention, vol. 83, pp. 162-170, 2015.

[4] S. C. Shackel and J. Parkin, "Influence of road markings, lane widths and driver behaviour on proximity and speed of vehicles overtaking cyclists," Accident Analysis \& Prevention, vol. 73, pp. 100-108, 2014.

[5] L. H. R. H. Zeuwts, P. Vansteenkiste, F. J. A. Deconinck, G. Cardon, and M. Lenoir, "Hazard perception in young cyclists and adult cyclists," Accident Analysis \& Prevention, vol. 105, pp. 64-71, 2017.

[6] Insurance Institute for Highway Safety. Fatality Facts Bicyclist. 2016. http://www.iihs.org/iihs/topics/t/pedestriansand-bicyclists/fatalityfacts/bicycles.

[7] NHTSA. Traffic Safety Facts 2014. 2016 https://crashstats.nhtsa .dot.gov/Api/Public/ViewPublication/812261.

[8] ERSO, European Road Safety Observatory. Traffic Safety Basic Facts - Cyclist. 2015.
[9] M. Räsänen and H. Summala, "Attention and expectation problems in bicycle-car collisions: an in-depth study," Accident Analysis \& Prevention, vol. 30, no. 5, pp. 657-666, 1998.

[10] J. M. Wood, P. F. Lacherez, R. P. Marszalek, and M. J. King, "Drivers' and cyclists' experiences of sharing the road: incidents, attitudes and perceptions of visibility," Accident Analysis \& Prevention, vol. 41, no. 4, pp. 772-776, 2009.

[11] J. K. Kim, S. Kim, G. F. Ulfarsson, and L. A. Porrello, "Bicyclist injury severities in bicycle-motor vehicle accidents," Accident Analysis \& Prevention, vol. 39, no. 2, pp. 238-251, 2007.

[12] E. Minikel, "Cyclist safety on bicycle boulevards and parallel arterial routes in Berkeley, California," Accident Analysis \& Prevention, vol. 45, no. 2, pp. 241-247, 2012.

[13] H. Summala, E. Pasanen, M. Räsänen, and J. Sievänen, "Bicycle accidents and drivers' visual search at left and right turns," Accident Analysis \& Prevention, vol. 28, no. 2, pp. 147-153, 1996.

[14] M. Rasanen and H. Summala, "Car Drivers' Adjustments to Cyclists at Roundabouts," Transportation Human Factors, vol. 2, no. 1, pp. 1-17, 2000.

[15] F. Bella and M. Silvestri, "Driver's braking behavior approaching pedestrian crossings: a parametric duration model of the speed reduction times," Journal of Advanced Transportation, vol. 50, no. 4, pp. 630-646, 2016.

[16] M. M. Haque and S. Washington, "The impact of mobile phone distraction on the braking behaviour of young drivers: A hazard-based duration model," Transportation Research Part C: Emerging Technologies, vol. 50, pp. 13-27, 2015.

[17] S. L. Hallmark, E. Peterson, E. Fitzsimmons, N. Hawkins, J. Resler, and T. Welch, Evaluation of gateway and low cost traffic calming measures for major routes in small rural communities, Center for Transportation Research and Education, Iowa State Univ, 2007.

[18] J. L. Campbell, C. M. Richard, and J. Graham, "Human Factors Guidelines for Road Systems," NCHRP Report 600B, TRB, Washington, DC, 2008.

[19] D. Collett, "Modelling survival data in medical research," Research Chapman \& Hall/CRC, vol. 2nd, 2003.

[20] Y. Chung, "Development of an accident duration prediction model on the Korean Freeway Systems," Accident Analysis \& Prevention, vol. 42, no. 1, pp. 282-289, 2010.

[21] A. Tavassoli Hojati, L. Ferreira, S. Washington, P. Charles, and A. Shobeirinejad, "Modelling total duration of traffic incidents including incident detection and recovery time," Accident Analysis \& Prevention, vol. 71, pp. 296-305, 2014.

[22] X. Yang, M. Huan, M. Abdel-Aty, Y. Peng, and Z. Gao, "A hazard-based duration model for analyzing crossing behavior of cyclists and electric bike riders at signalized intersections," Accident Analysis \& Prevention, vol. 74, pp. 33-41, 2015.

[23] J. Weng, Y. Zheng, X. Yan, and Q. Meng, "Development of a subway operation incident delay model using accelerated failure time approaches," Accident Analysis \& Prevention, vol. 73, pp. 12-19, 2014.

[24] Y.-S. Chung, Y.-C. Chiou, and C.-H. Lin, "Simultaneous equation modeling of freeway accident duration and lanes blocked," Analytic Methods in Accident Research, vol. 7, pp. 16-28, 2015.

[25] A. Tavassoli Hojati, L. Ferreira, S. Washington, and P. Charles, "Hazard based models for freeway traffic incident duration," Accident Analysis \& Prevention, vol. 52, pp. 171-181, 2013.

[26] Jr. Hosmer D. W. and S. Lemeshow, Applied Survival Analysis: Regression Modeling of Time to Event Data, John Wiley \& Sons, New York, NY, USA, 1999. 
[27] S. P. Washington, M. G. Karlaftis, and F. L. Mannering, Statistical and Econometric Methods for Transportation Data Analysis, CRC Press, Boca Raton, Fla, USA, 2nd edition, 2011.

[28] H. Akaike, "Information theory and an extension of the maximum likelihood principle," in Proceedings of the 2nd International Symposium on Information Theory (TSAhkadsor, 1971), B.N. Petrov and F. Csaki, Eds., pp. 267-281, Akademiai Kiado, Budapest, Hungary, 1973.

[29] G. Schwarz, "Estimating the dimension of a model," The Annals of Statistics, vol. 6, no. 2, pp. 461-464, 1978.

[30] F. Bella, "Driving simulator for speed research on two-lane rural roads," Accident Analysis \& Prevention, vol. 40, no. 3, pp. 10781087, 2008.

[31] F. Bella, "New model to estimate speed differential in tangentcurve transition," Advances in Transportation Studies an international Journal, vol. 15, pp. 27-36, 2008.

[32] F. Bella, "Driver perception of roadside configurations on two-lane rural roads: Effects on speed and lateral placement," Accident Analysis \& Prevention, vol. 50, pp. 251-262, 2013.

[33] F. Bella, "Driver Performance Approaching and Departing Curves: Driving Simulator Study," Traffic Injury Prevention, vol. 15, no. 3, pp. 310-318, 2014.

[34] F. Bella, "Operating speeds from driving simulator tests for road safety evaluation," Journal of Transportation Safety \& Security, vol. 6, no. 3, pp. 220-234, 2014.

[35] F. Bella and M. Silvestri, "Effects of safety measures on driver's speed behavior at pedestrian crossings," Accident Analysis \& Prevention, vol. 83, pp. 111-124, 2015.

[36] F. Bella and M. Silvestri, "Interaction driver-bicyclist on rural roads: Effects of cross-sections and road geometric elements," Accident Analysis \& Prevention, vol. 102, pp. 191-201, 2017.

[37] F. Bella and M. Silvestri, "Effects of directional auditory and visual warnings at intersections on reaction times and speed reduction times," Transportation Research Part F: Traffic Psychology and Behaviour, vol. 51, pp. 88-102, 2017.

[38] Ministry of Infrastructures and Transports. Decreto Ministeriale del 5/11/2001 Norme funzionali e geometriche per la costruzione delle strade. Roma, 2001 (in Italian).

[39] Ministry of Infrastructures and Transports. Nuovo codice della strada. D.L. 30/4/1992 n.285, Gazzetta Ufficiale Repubblica Italiana, n. 114. 1992 (In Italian).

[40] M. P. Allen, The problem of multicollinearity. Understanding Regression Analysis, Springer, Boston, MA, 1997.

[41] M. Cleves, G. William, R. G. Gutierrez, and Y. Marchenko, An Introduction to Survival Analysis Using Stata, Stata Press, College Station, Texas, 2nd edition, 2008.

[42] C. A. McGilchrist and C. W. Aisbett, "Regression with frailty in survival analysis," Biometrics, vol. 47, no. 2, pp. 461-466, 1991.

[43] F. Bella and M. Silvestri, "Drivers' Behavior at Bicycle Crossroads," in Advanced Concepts, Methodologies and Technologies for Transportation and Logistics, vol. 572 of Advances in Intelligent Systems and Computing, pp. 355-369, Springer International Publishing, Cham, 2018.

[44] F. Bella and M. Silvestri, "Driver-Cyclist Interaction Under Different Bicycle Crossroad Configurations," in Advances in Human Aspects of Transportation, vol. 597 of Advances in Intelligent Systems and Computing, pp. 855-866, Springer International Publishing, Cham, 2018.

[45] L. Leden, P. Gårder, and U. Pulkkinen, "An expert judgment model applied to estimating the safety effect of a bicycle facility," Accident Analysis \& Prevention, vol. 32, no. 4, pp. 589-599, 2000.
[46] H. Iasmin, A. Kojima, and H. Kubota, "Safety effectiveness of pavement design treatment at intersections: Left turning vehicles and pedestrians on crosswalks," IATSS Research, vol. 40, no. 1, pp. 47-55, 2016.

[47] V. Perepjolkina and V. Reņge, "Drivers' Age, Gender, Driving Experience, and Aggressiveness as Predictors of Aggressive Driving Behaviour," Journal of Pedagogy and Psychology "Signum Temporis", vol. 4, no. 1, 2011.

[48] D. Jovanović, K. Lipovac, P. Stanojević, and D. Stanojević, "The effects of personality traits on driving-related anger and aggressive behaviour in traffic among Serbian drivers," Transportation Research Part F: Traffic Psychology and Behaviour, vol. 14, no. 1, pp. 43-53, 2011.

[49] R. Lawton, D. Parker, A. S. R. Manstead, and S. G. Stradling, "The role of affect in predicting social behaviors: The case of road traffic violations," Journal of Applied Social Psychology, vol. 27, no. 14, pp. 1258-1276, 1997.

[50] J. Törnros, "Driving behaviour in a real and a simulated road tunnel - A validation study," Accident Analysis \& Prevention, vol. 30, no. 4, pp. 497-503, 1998. 


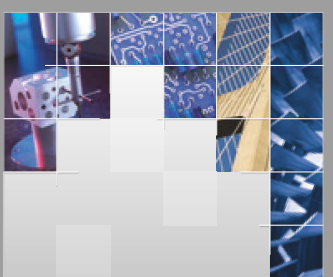

\section{Enfincering}
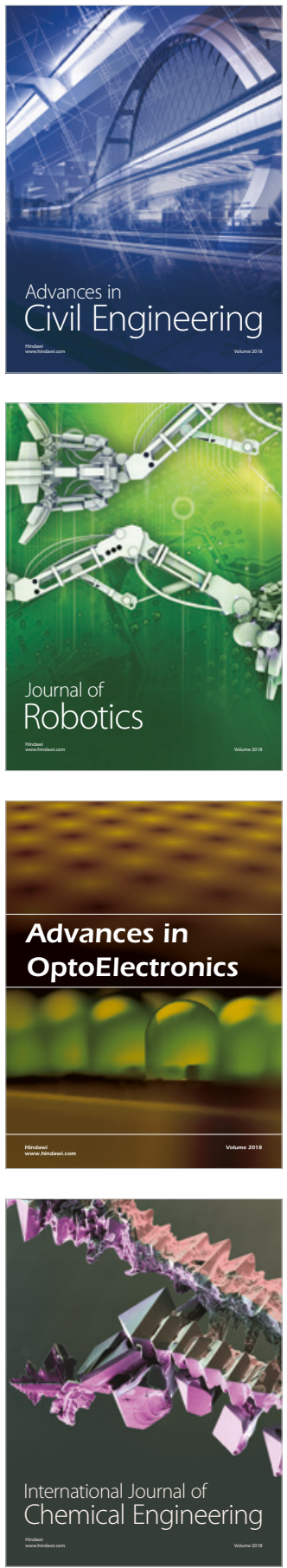

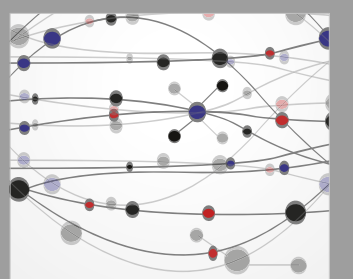

\section{Rotating \\ Machinery}

The Scientific World Journal

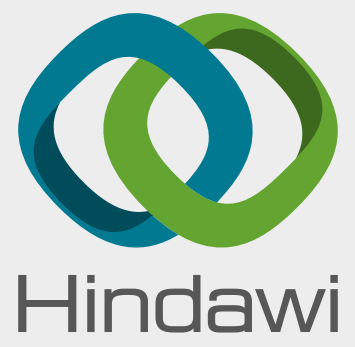

Submit your manuscripts at

www.hindawi.com
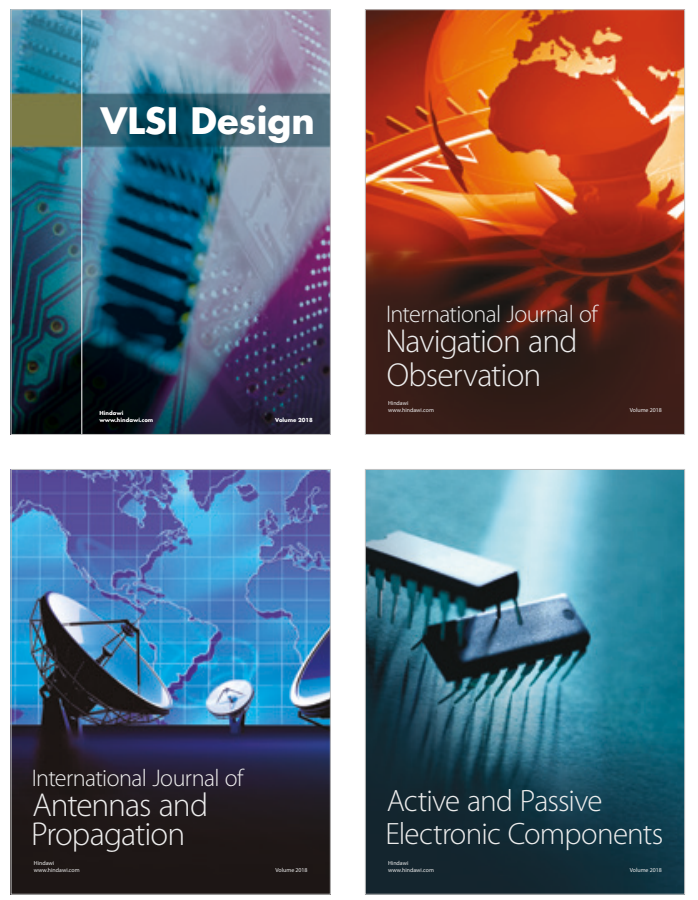
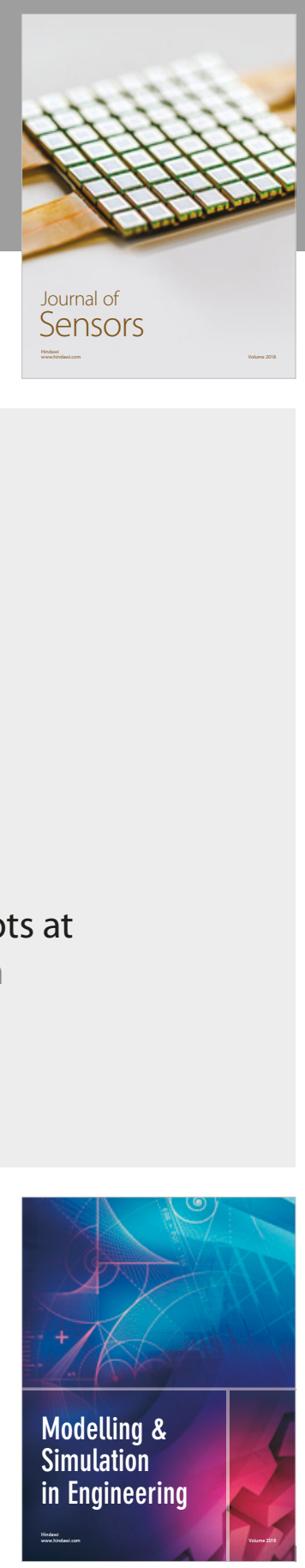

\section{Advances \\ Multimedia}
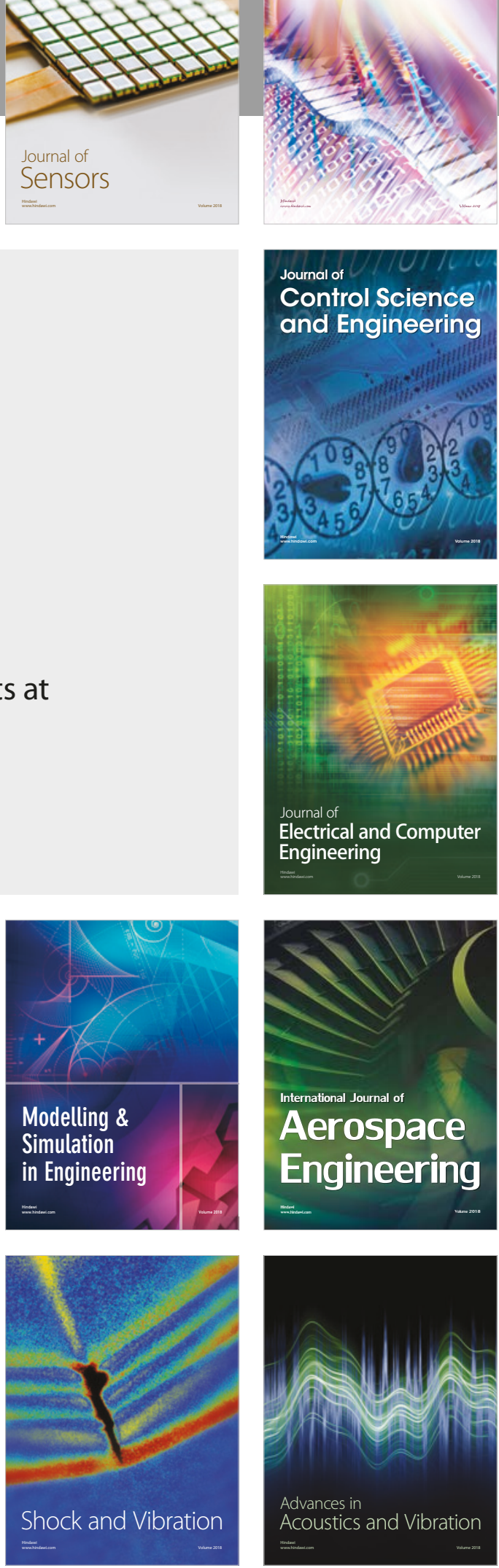